\title{
25 Research Soure \\ Plants for Making Tibetan Traditional Wooden Bowls and Related Traditional Knowledge in the Gyirong Valley, Tibet, China
}

\section{Xiaoyong Ding}

Yunnan Key Laboratory for Wild Plant Resources, Kunming Institute of Botany, Chinese Academy of

Sciences, Kunming, China

\section{ChangAn Guo}

Chinese Academy of Sciences

\section{HuaBin Hu}

CAS Key Laboratory of Tropical Plant Resources and Sustainable Use, Xishuangbanna Tropical Botanical Garden, Chinese Academy of Sciences, Mengla 666303, Yunnan, China.

Yuhua Wang ( $\nabla$ wangyuhua@mail.kib.ac.cn )

Yunnan Key Laboratory for Wild Plant Resources, Kunming Institute of Botany, Chinese Academy of

Sciences, Kunming, China

\section{Research Article}

Keywords: Tibet, Tibetan, Traditional wooden bowl, Ethobotany

Posted Date: November 11th, 2021

DOI: https://doi.org/10.21203/rs.3.rs-1063056/v1

License: (a) (i) This work is licensed under a Creative Commons Attribution 4.0 International License. Read Full License 


\section{Abstract}

Background: The wooden bowl is an important symbol of the Tibetan cultures, yet, in China, little has been documented regarding the raw materials used to make these items as well as their cultural significance in Tibet. This study explores the ethnobotanical uses of plants used to make wooden bowls to understand their sustainability, cultural significance, and current status of related traditional knowledge in Gyirong Town, which is one of the most famous places for wooden bowl making.

Materials and methods: Between 2019 and 2021, key informant interviews, semi-stuctured interviews, and participatory observations were used to conduct ethnobotanical field surveys in Gyirong Valley. The field work was performed with the assistance of local guides. In this study, we utilised a use-report (UR) and relative frequency citation (RFC) to evaluate the value and importance of the species used to make the wooden bowls..

Results: Our results show that 16 different plants are used during the wooden bowl making process, of which nine are used as raw materials, three for dyeing, and four for varnishing. Although communities rely heavily on these plants, good management and collection methods were observed. We also recorded the use of Fallopia denticulata as a red dye and four species of Impatiens as wood lacquers for the first time.

Conclusion: We found no significant difference in the knowledge of the traditional use of plants among people of different ages and genders in Gyirong; traditional knowledge is widespread among family members and among different villages. The government and local people are committed to the protection and development of traditional knowledge related to wooden bowls, and this knowledge maintains a healthy degree of vitality. This research can provide insights into the vitality of traditional handicrafts that are facing challenges and promote their protection.

\section{Background}

Tibetans are one of 56 ethnic groups in China and have lived in the Qinghai-Tibet Plateau region for generations. The use of wooden bowls by Tibetans has a long history and is one of the necessities of Tibetan life, now an important symbol of Tibetan culture [1]. These wooden bowls made in many places, but communities in Cuo na, Jia cha, Gyirong, and Cha yu are particularly well known for their bowl-making skills. The craftsmanship in Gyirong and Cha yu wooden bowls has led to their recognition as a type of regional intangible cultural heritage of the region [2].

The technique, artistic value and cultural connotation contained in handicraft products are all important aspects of intangible cultural heritage [3]. The handicraft industry also plays a vital role in generating income and employment $[4,5]$, and is recognized as a tool for poverty reduction worldwide. Indeed, in many developing countries, the handicraft industry is an important income sector second only to agriculture [6]; however, the handicraft industry faces some challenges, such as industrialization and globalization [7]. Moreover, due to the lack of sufficient data on handicraft practices, this sector remains at a disadvantage [7, 8], which hinders protection measures [9]. Although wooden bowls are an indispensable 
part of Tibetan life and an important source of income for local Tibetans, documention of the making process remains poor. Furthermore, studies that have made only mentioned local plant names while specific scientific names have not been recorded $[10,11]$. Huang describes that the coloring and lacquering of Tibetan wooden bowls generally involves the juice of "jia-yu-cao" as a pigment, which grows in mountainous areas [11]. Building on this sparse information we aimed to (1) record the traditional Tibetan plants and knowledge of wooden bowl makings in Gyirong Town, (2) explore the cultural significance of these plants, and (3) explore the local use of these plants in the context of socio-economic change.

In addition, ethnobotanical studies have shown that species with high use value are subject to intensive harvesting activities $[12,13]$. Therefore, we also considered the sustainability of the targeted plantharvesting practices for wooden bowl making in Gyirong given wider potential ecological consequences for endangered endemic species [14].

\section{Materials And Methods 2.1 Study area}

Gyirong Town is known as the "Back Garden of the Himalayas" and is located in the core area of the Everest National Nature Reserve to the south of Shigatse City in the Tibet Autonomous Region of China (Fig. 1). The total population of the town was 3,946 in 2017, and the main ethnic group is Tibetan. This area has a subtropical monsoon climate with an annual average temperature of $10-13^{\circ} \mathrm{C}$ (temperatures during the warmest months exceed $18{ }^{\circ} \mathrm{C}$ ), an annual precipitation of $230-370 \mathrm{~mm}$, and more than 200 frost-free days annually. Gyirong Town is dominated by low altitude forest dominated by Pinus griffithii, $P$. roxburghii, Picea smithiana, Tsuga dumosa, Betula utilis, Abies spectabilis, Sabina chinensis, and Cuculus $s p p$. This rich forest resource provides sufficient raw materials for traditional wooden bowl makings.

\subsection{Data collection}

Between 2019 and 2021, key informant interviews, semi-stuctured interviews, and participatory observations were used to conduct ethnobotanical field surveys. To help understand the traditional knowledges of different stakeholders associated with Gyirong wooden bowls, traditional craftsmen and merchants were selected as key informants. The "snowballing" method was used to identify the wooden bowl craftsmen, and random interviews were conducted of the merchants. A total of 51 informants (27 men and, 24 women) were interviewed, all of whom provided informed consent before the interviews. Due to relatively poor levels of education, most local people, especially community elders, could not communicate fluently in Chinese. Therefore, fieldwork was conducted with the assistance of local guides. The key informant and semi-strctured interviews were conducted based on the following questions: (1) What tree can be used to make wooden bowls? (2) Which tree is the best? and why? (3) What plant do you use to dye the wooden bowls? (4) What plant do you use to varnish the wooden bowls? (5) What cultural significance do these plants have? 
During the field surveys, we collected plant specimens with the help of the local guides, which were later identified based on taxonomic groups with the aid of digital photographs. Permissions to take samples were always obtained from the informants and relevant local community departments. The specimens were identified and preserved in the herbarium of the Kunming Institute of Botany, Chinese Academy of Sciences (KUN), and the attributed scientific names were checked using "The Plant List." (www.theplantlist.org).

\subsection{Data analysis}

We adopted the use report (UR) and relative frequency citation (RFC) as ethnobotanical indices [15]. The $\mathrm{RFC}$ index (RFC=FC/N) was then used to evaluate the value and importance of the species used to make the wooden bowls. This index describess the proportion of the total number of respondents who mentioned that a species is useful (FC) accounting for all informants in the survey (N) and irrespective of the use category of the species. The higher the RFC index value of a species, the more important it is considered to be in the study area.

Then use the social science statistics package (IBM SPSS version 20.0) to perform Student t-test and Pearson correlation coefficient on the converted data to compare the traditional knowledge of people of different ages and genders and the significance level is set to 0.05 .

\section{Results And Discussion}

\subsection{Plants for making wooden bowls and their sustainable management}

Through our interviews and fieldworks, we identified nine plant species (eight family and, nine genera) used as raw materials for making wooden bowls in Gyirong Town. All of these species were the dominant local vegetation types, indicating the sufficient availability of raw material resources. The quality of the wooden bowls produced using the different plants varies, with local people showing some particular preference. For example, Betula utilis was most mentioned (RFC $=1$ ) for making wooden bowls because its wood does not crack or discolor, and the more that $B$. utilis bowls are used, the redder their color becomes. In contrast, bowl made using Rhododendron arboreum (RFC $=0.22$ ) easily deform over time. Because of the hardness of its wood, Quercus semecarpifolia (RFC $=0.22$ ) is relatively difficult to work with, and the resulting bowls easily crack. As well as such differences between species, wooden bowls made from different parts of the same plant can have different properties, which is reflected in their monetary value. For example, a bowl made from wood obtained from a tree trunk costs approximately $\$ 10$, while a bowl made from burl wood can sell for \$200-400. Indeed, burls are considered the best souece of wood for bowl making by local Tibetans as these tend to produce items with the most beautiful patterns (Fig. 2a). Bowls made of burl are called "cha-bo-luo" meaning they can last a lifetime; "cha-bo-luo" bowls are considered the best dowry and betrothal gifts, cherished carefully look after by their recipients. These 
specific types of bowls are slso one of the most valued blessings passed between parents and their children for a happy life.

Non-timber forest products provide a variety of cultural and economic values for those ethnic groups that depend on forests [15]. However, whether target species for cultural and economicuse can be managed sustainably remains a matter of debate. This includes Juniperus Tibetica (VU), which the International Union for Conservation of Nature (IUCN) has claasified as a vulnerable species [16]. During our interviews, we learned about the forest management practices of the local people, which follow a general set of collection guidelines for $B$. utilis, the most-used species in the area. Notably, local people believe that dead trees are the best raw material. For example, an earthquake that occurred on April 25, 2014, destroyed many $B$. utilis that were subsequently used to make wooden bowls. Harvesting time is also crucial, with the wood collected before the rainy season to preserve the valued patterns in the wood. These practices can be thought of as a sustainable management in Gyirong, much like "thinning" in other managed forests [17]. Furthermore, in recent years, the local government has stipulated that it is forbidden to fell certain tree species, including J. tibetica, and others can only be cut down three days of these year.

\section{Table 1}

plants for making wooden bowls

\begin{tabular}{|c|c|c|c|c|c|}
\hline Scientific name & $\begin{array}{l}\text { Venecular } \\
\text { name }\end{array}$ & $\begin{array}{l}\text { URs of } \\
\text { men }\end{array}$ & $\begin{array}{l}\text { URs of } \\
\text { women }\end{array}$ & RFC & $\begin{array}{l}\text { Vocher } \\
\text { Number }\end{array}$ \\
\hline Betula utilis D. Don & $D a-b a$ & 27 & 24 & 1 & QTB-JL-7 \\
\hline Juniperus tibetica Komarov & Xiu-bai & 11 & 16 & 0.48 & $\begin{array}{l}\text { QTB-JL- } \\
64\end{array}$ \\
\hline Quercus semecarpifolia Smith & Bai-lou & 6 & 7 & 0.22 & $\begin{array}{l}\text { QTB-JL- } \\
25\end{array}$ \\
\hline Salix trichocarpa C. F. Fang & Lang-ma & 4 & 0 & 0.08 & $\begin{array}{l}\text { QTB-JL- } \\
47\end{array}$ \\
\hline Pinus wallichiana A. B. Jackson & Tang-xin & 2 & 4 & 0.12 & $\begin{array}{l}\text { QTB-JL- } \\
39\end{array}$ \\
\hline Rhododendron arboreum Smith & Mei-duo & 4 & 8 & 0.22 & $\begin{array}{l}\text { QTB-JL- } \\
30\end{array}$ \\
\hline- & Long-xin & 3 & 4 & 0.14 & - \\
\hline Larix himalaica Cheng et L. K. Fu & Jia-xin & 1 & 0 & 0.02 & $\begin{array}{l}\text { QTB-JL- } \\
125\end{array}$ \\
\hline $\begin{array}{l}\text { Himalayacalamus falconeri (Hook.f. ex } \\
\text { Munro) Keng f. }\end{array}$ & Zha-bi-ya & 1 & 0 & 0.02 & $\begin{array}{l}\text { QTB-JL- } \\
118\end{array}$ \\
\hline
\end{tabular}




\subsection{Plants used for dying wooden bowls and their cultural significance}

Traditionally, natural plant pigments have been discovered and used by people all over the world to dye a range of materials various colors, whether for esthetic or cultural meaning, including wishes for a good harvest, health, and wealth, or to produce auspicious images worshiped by local people. For example, the Miao people living in Sanshui, China, dye bamboo slices that are woven into handicrafts icorporating auspicious images, characters, flowers, and animals worshiped [18]. In Tibet, wooden bowls are dyed in yellow and red, having the meanings of good luck and happiness, respectively. In Tibetan Buddhism, yellow represents the flourishing land, and red often represents fire as well as being a symbol of power. Tipically, dried Rheum australe roots and the bark of Berberis xanthophlaea are used by locals in Gyirong to produce yellow dyes. These raw materials are first boiled in water for 30 minutes and then unfinished (rough) wooden bowls are completely submerged in the cooled dye solution for coloring approximaately 30 seconds and, finally, allowed to dry in the sun. Rheum australe and Fallopia denticulata are used as red dyes in the same way (Fig. 2e-f). The srength of the dye solutions depends on the type and color of the wood. For example, some wood (B. utilis) is "white", requiring a stronger dye solution, while some types of wood are already "dark" in color and require a lighter dye solution. Notably, we made the first observation of $F$. denticulata being used for producing a dye. While traditional wooden bowl makers still use these dying methods, many others now use industrial dyes. In Gyirong, the yellow color of traditional Tibetan wooden bowl is still achieved using plant-based dyes, surviving as a deeply rooted cultural practice.

Table 2

Plants used for dying wooden bowls

\begin{tabular}{llll} 
Scientific name & Vernacular name & Use parts & Vocher Number \\
\hline Rheum australe D. Don & Qu-zha & Rhizome & QTB-JL-3 \\
\hline Berberis xanthophlaea Ahrendt & Giu-lu & Bark and root & QTB-JL-28 \\
\hline Fallopia denticulata (C.C.Huang) Holub & A-lang-ba-lang & Rhizome & QTB-JL-33
\end{tabular}

\subsection{Plants traditionlly used as varnishes}

The term varnish refers to "a liquid that dries into a transparent film when applied to a solid surface" [19]. Wood varnishes not only protect the wood from weathering, abrasion, and environmental humidity fluctuations, but also have a certain decorative aesthetic function [19, 20]. In Gyirong, Impatiens falcifer, I. bicornuta, I. sulcata, and I. scabrida are used by locals to produce natural varnishes or lacquers (Table 3), which is also the first known record of using of this genus of plants in this way. At the beginning of October each year, the local people collect mature Impatiens seeds, dry them, grind them, and coat the pre- 
stained wooden bowls with the resulting oils. This process needs to be repeated at least three or four times. A similar process is reported to have been used for mor than 7,000 years in Chinese culture [21, 22]. The traditional wooden bowl lacquers used in the Sichuan Province, Yunnan Province, and Tibet Region of China mainly consist of clay and tung oil purchased from the surrounding Lisu people [1]. Although lacquer-containing Toxicodendron acuminatum and T. wallichii are found around the Gyirong Valley, they are not used by the locals [23]. This may be because local people wish to highlight the yellow and red dyes applied to their traditional bowls, and "raw lacquer" has quite a deep color; the natural dyes can be obscured by the color of the raw lacquer, with ancient Chinese lacquer mostly black and vermilion [24]. The unsaturated fatty acids content of $I$. balsamina seed oil is $70.75 \%$, including $16.50 \%$ linoleic acid and $31.47 \%$ a-linolenic acid [25]. These substances penetrate into the wood, having a moisturize a preservative effet that highlights natural texture similar to Wood Wax Oil, which is $90 \%$ unsaturated fatty acids $[26,27]$. Therefore, Impatiens varnish or lacquer is favored over that produced from Toxicodendron by the trditional wooden bowl makers in Gyirong.

Traditional knowledge is often holistic and adaptive, gathered by generations of observers whose lives depend on this information and its use [28]. As an embodiment of the relationship between humans and biota, plant utilization fully reflects and supports the characteristics of culture, ideology and technology that existed at any given time in human history [29]. The process of re-selection and utilization of Impatiens plants by the Tibetans of Gyirong is a good example of this relationship. In the past, Gyirong wooden bowls were mainly produced in Naixia Village and were used by Tibetans in nearby towns and villages. With the development of society and tourism, Gyirong wooden bowls have become well known for their high quality and low price, and their demand is increased rapidly as a consequence. Due to the low yields of Impatiens seeds and the complicated processing procedures, traditional natural lacquer has been gradually replaced by modern industrial varnishes for over the past 30 years. However, commercial varnishes have one serious disadvantage. Although these varnishes can be easily purchased and application is relatively simple, they retain a pungent smell for a long period, which can have some health risks. In Gyirong, attempts are made to remove this smell by soaking the varnished wooden bowls in wine made from highland barley for half an hour,although this does not completely remove the smell. Perhaps most crucially, varnishing wooden bowls with commercial varnishes does not appear to improve sales. In contrast, a wooden bowl cooperative has been recently organized by the local people to promote the use the original Impatiens-based wood varnish. This have been favored by tourists, and sales have increased significantly as a result both in self-opeated and online stores. As such, Impatients species in this area are more than just a traditional natural varnish or lacquer plant, but demonstrate the ability of local local Tibetans to adapt to modern society. Such adaptation relies on locally accumulated traditional [30].

\section{Table 3}

Traditional wooden bowl varnishes 


\begin{tabular}{|llll|}
\hline Scientific name & Vernacular name & Use part & Vocher Number \\
\hline Impatiens falcifer Hook.f. & Po-zhi & Seed & QTB-JL-15 \\
\hline Impatiens bicornuta Wall. & Po-zhi & Seed & QTB-JL-73 \\
\hline Impatiens sulcata Wall. & Po-zhi & Seed & QTB-JL-62 \\
\hline Impatiens scabrida DC. & Po-zhi & Seed & QTB-JL-70 \\
\hline
\end{tabular}

\subsection{Status and trends of Tibetan wooden bowls in Gyirong Valley}

In studies exploring the factors that influence traditional knowledge about plants, gender and age are usually considered most [31]. Generally, the gender division of labor in traditional societies partly explains differences in knowledge between men and women [32]. In Gyirong Town, although the making of traditional wooden bowls is the exclusive job of men, no significant age $(p=0.370)$ or gender $(p=0.536)$ differences were observed in the levels of knowledge about this as a cultural practice (Table 4). Our ethnobotanical survey results show a total of 122 use reports (59 URs from men and 62 from women) referring to nine plant species. All nine plants were listed by men while, six plants were listed by women. Plants used to obtain dyes and varnish were both mentioned by men and women. From the perspective of the social division of labor, although processing wooden bowls is exclusively undertaken by men (Fig. 2bd), women are involved in stages of the making process (Fig. 2a, e-h). Given that all our informants had a low level of formal education, their knowledge about plants and their uses derives from working for their parents from an early age. In this way, the collaboration and division of labor among family members in Gyirong has allowed the traditional knowledge of wooden bowl making to be passed on between generations.

The wooden bowl production process is complicated, involving a series of procedures: including material selection, air drying, carving, dying, and varnishing (Fig. 2). According to our interviews and observations, it took several days to select the materials, and the raw materials must be placed for two to three months before they can be used. Rough processig is then required, taking approximately four hours. Finally, dyeing and varnishing takes approximately one week. In addition, according to the local craftsmen, there has be poor demand for ordinary wooden bowls over the last few decades, with generally poor profits as a result. Fewer local people make these items as a result, with many more choosing to seek work elsewhere. In the past, wooden bowls were only processes in Nai village. Then, in 2008, the traditional wooden bowl-making process was selected, under the organization of the Gyirong Government, to be included on the Tibet Autonomous Region Intangible Cultural Heritage List [2]. At the same time, some people in other villages began to learn traditional techniques from their elders, and more began to process and sell wooden bowls. More recently, the Gyirong Town Government has helped farmers and herdsmen register 51 professional cooperatives, including 12 processing and manufacturing cooperatives. This has helped spread traditional 
knowledge about wooden bowl making from Nai to other villages. In addition, the popularization of tourism and e-commerce has increased demand for these items. Villages with good tourism benefit from the wholesale of wooden bowls from Nai Village and Zha Village, further broadening the sales channels. Currently, craftsmen can earn up to $\$ 4,000$ each year from selling traditional wooden bowls, which are often made outside of the farming season. This additional income has become a powerful tool for local poverty alleviation .

Multiple challenges such as industrialization and globalization affect the development of handicraft industries worldwide [7,33]. In the case of wooden bowls, knowledge is passed within family generationss in Gyirong through the traditional division of labor. Under the guidance of the modern social government and the motivation of higher income, this knowledge has been spread from village to village, further enhancing the vitality of this local knowledge. Research on Chinese Sanshui bamboo weaving also confirms the role of local government in facilitating the inheritance and development of handicrafts skills and practices [18]. In addition, the local people in Gyirong resilience to the rapid changes occurring around them, such as the use of four species of Impatiens for producing varnishes.

Table 4

\section{Results of student t-test of local knowledge of different genders and Pearson Correlation of local knowledge of different ages.}

\begin{tabular}{|lllll|}
\hline & \multicolumn{2}{l}{ Student-test } & \multicolumn{2}{l|}{ Pearson Correlation } \\
\hline Man & Woman & Sppknown & Age \\
\hline Standard deviation & 2.370 & 2.625 & 2.490 & 49.315 \\
\hline r & 1.548 & 1.345 & 1.447 & 15.368 \\
\hline P-value & - & & 0.128 & \\
\hline Sppknown: The number of species known to people of different ages; r: Correlation coefficient. \\
\hline
\end{tabular}

\section{Conclusions}

We studied the plants used in traditional Tibetan wooden bowl making in Gyirong Town, China, which included nine species belonging to nine genera. One of these species, J. tibetica (VU) is identified as vulnerable by the IUCN. Although communities rely heavily on these plants, good management and collection practices were observed. $B$. utilis is the most commonly used species for bowl making because of its excellent characteristics. Bowls made from B. utilis burls are called "cha-bo-luo", which are highly valued as dowry and betrothal gifts. The wooden bowls are dyed in yellow and red, signifying good luck and happiness, respectively. Yellow dyes are made from $R$. australe and B. xanthophlaea, and $R$. 
australe and F. denticulata are used to make red dyes. I. falcifer, I. bicornuta, I. sulcata, and I. scabrida are also used as varnish by the Tibetans in Gyirong. This is the first record of $F$. convolvulus being used to make red dye, and the first time these four species of Impatiens has been recorded for use as wood varnishes.

We found no significant difference in the levels of knowledge of traditional plants use among different age and gender groups in Gyirong. The traditional craft of making wooden bowls has been well preserved among family members and between villages, and shows strong vitality. Notably, the continued use of Impatiens seed oils as varnishes over commercially available varnishes serves to demonstrate the resilience of these local communities and their traditional crafts. In the face of industrialization alongside the adaptability of local craftsmen and, their wider communities, government support and guidance are highlighted as powerful tools to help protect and develop this fragile intangible cultural heritage. This case study provides inspiration for traditional handicrafts that are facing challenges elsewhere.

\section{Declarations}

\section{Acknowledgements}

We are very grateful to the informants for sharing their knowledge with us. We thank Professor Pei Shengji for technical guidance. In addition, we thank Mr. Xu Haikun as auto drivers in the wild works.

\section{Authors' contributions}

WYH organized the study team and provided technical support and guidance. DXY and GCA designed and executed the research plan. DXY wrote the manuscript. GCA and HHB recorded and organized the data. DXY and GCA identified the specimen and checked the information. All authors took part in the field works. All authors were involved in the drafting and revision of the manuscript and approved the final revision.

\section{Funding}

The study was funded by "the Second Tibetan Plateau Scientific Expedition and Research (No. 2019QZKK0502)".

\section{Availability of data and materials}

Please contact the corresponding author for data requests.

\section{Ethics approval and consent to participate}


The authors asked for permission from the local authorities and the people interviewed to carry out the study.

\section{Consent for publication}

The people interviewed were informed about the study's objectives and the eventual publication of the information gathered, and they were assured that the informants' identities would remain undisclosed.

\section{Competing interests}

The authors declare that they have no competing interests.

\section{Author details}

${ }^{1}$ Yunnan Key Laboratory for Wild Plant Resources, Kunming Institute of Botany, Chinese Academy of Sciences, Kunming, China. ${ }^{2}$ University of Chinese Academy of Sciences, Beijing, China. ${ }^{3}$ CAS Key Laboratory of Tropical Plant Resources and Sustainable Use, Xishuangbanna Tropical Botanical Garden, Chinese Academy of Sciences, Mengla 666303, Yunnan, China.

\section{References}

1. He M, He JB. Yunnan, Sichuan and Tibet]. Acad Explor. 2015; 000 (002): 78-83; doi: 10.3969/j.issn.1006723X.2015.02.013.

2. The People's government of Tibet Autonomous Region. intangible cultural heritage of the Tibet Autonomous Region]. . Accessed 15 Sept 2021.

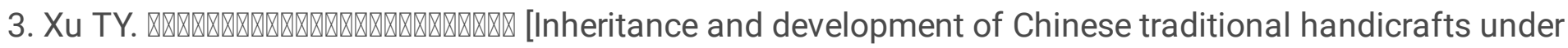
the background of intangible cultural heritage protection]. Light Text Ind Tech. 2020; 49 (6): 3; doi: 10.3969/j.issn.2095-0101.2020.06.023.

4. Jones $\mathrm{E}$, Smith S, Wills $\mathrm{C}$. Women producers and the benefits of collective forms of enterprise. Gender Dev. 2012; 20 (1): 13-32; doi: 10.2307/23408745.

5. Fatt BS, Bakansing SM. An alternative raw material in handicraft-making by using the oil palm fronds: A community based tourism exploratory study at Kota Belud, Sabah. Tour Leis Glob Change. 2014; 1: 25-37.

6. Paige RC. Profiles of successful craft micro-retailers. J Dev Entrepreneurship. 2009; 14: 393-412; doi: 10.1142/S1084946709001326.

7. Barber T, Krivoshlykova M. Global market assessment for handicrafts. Washington, DC: USAID; 2006. 1: 1-78. 
8. Rogerson CM. The enterprise of craft: constraints and policy challenges in South Africa. Acta Acad. 2010; 42 (3): 115-144; doi: ISSN 0587-2405.

9. Grobar LM. Policies to promote employment and preserve cultural heritage in the handicraft sector. Int J Cult Policy. 2017; 2: 1-13; doi: 10.1080/10286632.2020.1842382.

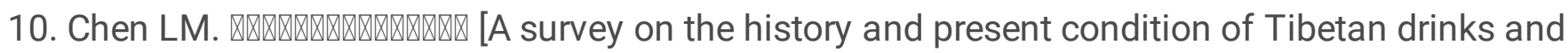
kitchenware]. J Southwest Univ Nationalities (philos soc sci) 23 (3): 18-21; doi: CNKI:SUN:XNZS.0.2002-03-003.

11. Huang AH. 姆国四 [Tibetan tea-urn and Kitchenware]. J Aba Teaches College. 2008; 25 (1): 33-36; doi:CNKI:SUN:ABSF.0.2008-01-010.

12. Albuquerque UP, Lucena RFP, Monteiro JM, Florentino ATN, Cecília de Fátima Almeida CBR. Evaluating two quantitative ethnobotanical techniques. Ethnobot Res Appl. 2006; 4 (1): 51-60; doi: 10.17348/era.4.0.51-60.

13. Kalle R, Sõukand R. Current and remembered past uses of wild food plants in Saaremaa, Estonia: Changes in the context of unlearning debt. Econ Bot. 2016; 70 (3): 235-253; doi: 10.1007/s12231-0169355-x.

14. Ticktin T. The ecological implications of harvesting non-timber forest products. J Appl Ecol. 2004; 41 (1): 11-21; doi: $10.2307 / 3505876$.

15. Pandey AK, Tripathi YC, Kumar A. Nontimber forest products (NTFPs) for sustained livelihood: Challenges and strategies. Res J For. 2016; 10 (1): 1-7; doi: 10.3923/rjf.2016.1.7.

16. IUCN 2021. The IUCN Red List of Threatened Species. Version 2021-2. . Accessed 10 Oct 2021.

17. Russell ES, Liu H, Thistle H, Strom B, Greer M, Lamb B. Effects of thinning a forest stand on subcanopy turbulence. Agric For Meteorol. 2018; 248: 295-305; doi: 10.1016/j.agrformet.2017.10.019.

18. Luo BS, Ahmed S, Long CL. Bamboos for weaving and relevant traditional knowledge in Sansui, Southwest China. J Ethnobiol Ethnomed. 2020; 16 (1): 63; doi: 10.1186/s13002-020-00418-9.

19. Gilani MS, Pflaum J, Hartmann S, Kaufmann R, Baumgartner M, Schwarze F. Relationship of vibromechanical properties and microstructure of wood and varnish interface in string instruments. Appl Phys A. 2016; 122 (4 pt. 1): 1-11; doi: 10.1007/s00339-016-9670-1.

20. Yalinkilic MK, Ilhan R, Imamura Y, Takahashi M, Demirci Z, Yalmkilic AC, Peker H. Weathering durability of CCB-impregnated wood for clear varnish coatings. J Wood Sci. 1999; 45 (6): 502-514; doi: 10.1007/BF00538961.

21. Shen H. Textual research of China coatings 7000 years history. China Coating. 2011; 26 (1): 65-68; doi: 10.13531/j.cnki.china.coatings.2011.01.017.

22. Sung M, Jung J, Lu R, T. Study of historical Chinese lacquer culture and technology - Analysis of Chinese Qin-Han dynasty lacquerware. J Cult Herit. 2016; 21 (14): 889-893; doi: 10.1016/j.culher.2016.05.004.

23. Zheng JM. 㽖因 [Lacquer trees in Tibet]. J Chinese Lacquer. 1982; 01: 6-10; doi: 10.19334/j.cnki.issn.1000-7067.1982.01.003. 
24. Fang J. The study of function and cultural connotation of lacquer in ancient China. J Chinese Lacquer. 2017; 36 (3): 14-21; doi: 10.19334/j.cnki.issn.1000-7067.2017.03.003.

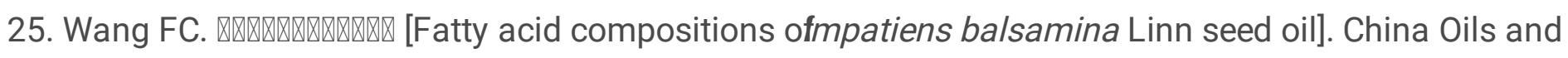
Fats. 2008; 208 (06): 78-79; doi:CNKI:SUN:ZYZZ.0.2008-06-025.

26. Nussbanm RM, Stucliffe EJ, Hellgren AC. Microautoradiographic studies of the penetration of alkyd emulsion and linseed oil coatings into wood. J Coat Technol. 1998; 70 (3): 49-57; doi: 10.1007/BF02697811.

27. Huang YH, Feng QM, Dong TY, Ye CY, Li F. Brief analysis of the application research status and development tendency of wood wax oil. China For Prod Ind. 2019; 46 (1): 7-11; doi: 10.19531/j.issn1001-5299.201901002.

28. Berkes F, Colding J, Folke C. Rediscovery of traditional ecological knowledge as adaptive management. Ecol Appl. 2000; 10 (5): 1251-1262; doi: 10.2307/2641280.

29. Bates DM. Plant utilization: Patterns and prospects. Econ Bot. 1985; 39 (3): 241-265; doi: $10.1007 /$ bf02858794.

30. Ohmagari K, Berkes F. Transmission of indigenous knowledge and bush skills among the western James Bay Cree women of subarctic Canada. Hum Ecol. 1997; 25 (2): 197-222; doi: 10.1023/A:1021922105740.

31. Albuquerque UP, GT, SS, Ramos MA, de JC, LC. The use of plants in the medical system of the Fulni-ô people (NE Brazil): A perspective on age and gender. J Ethnopharmacol. 2011; 133 (2): 866-873; doi: 10.1016/j.jep.2010.11.021.

32. Jackson C. Gender analysis and environmentalism. In: Redclift, M., Benton, T. (Eds.), Social theory and the global environment. Routledge, New York, NY; 1994. pp. 113-149.

33. Yang $Y$, Shafi M, Song $X$, Yang R. Preservation of cultural heritage embodied in traditional crafts in the developing countries. A Case Study of Pakistani handicraft industry. Sustainability. 2018; 10 (5): 1336; doi: 10.3390/su10051336.

\section{Figures}




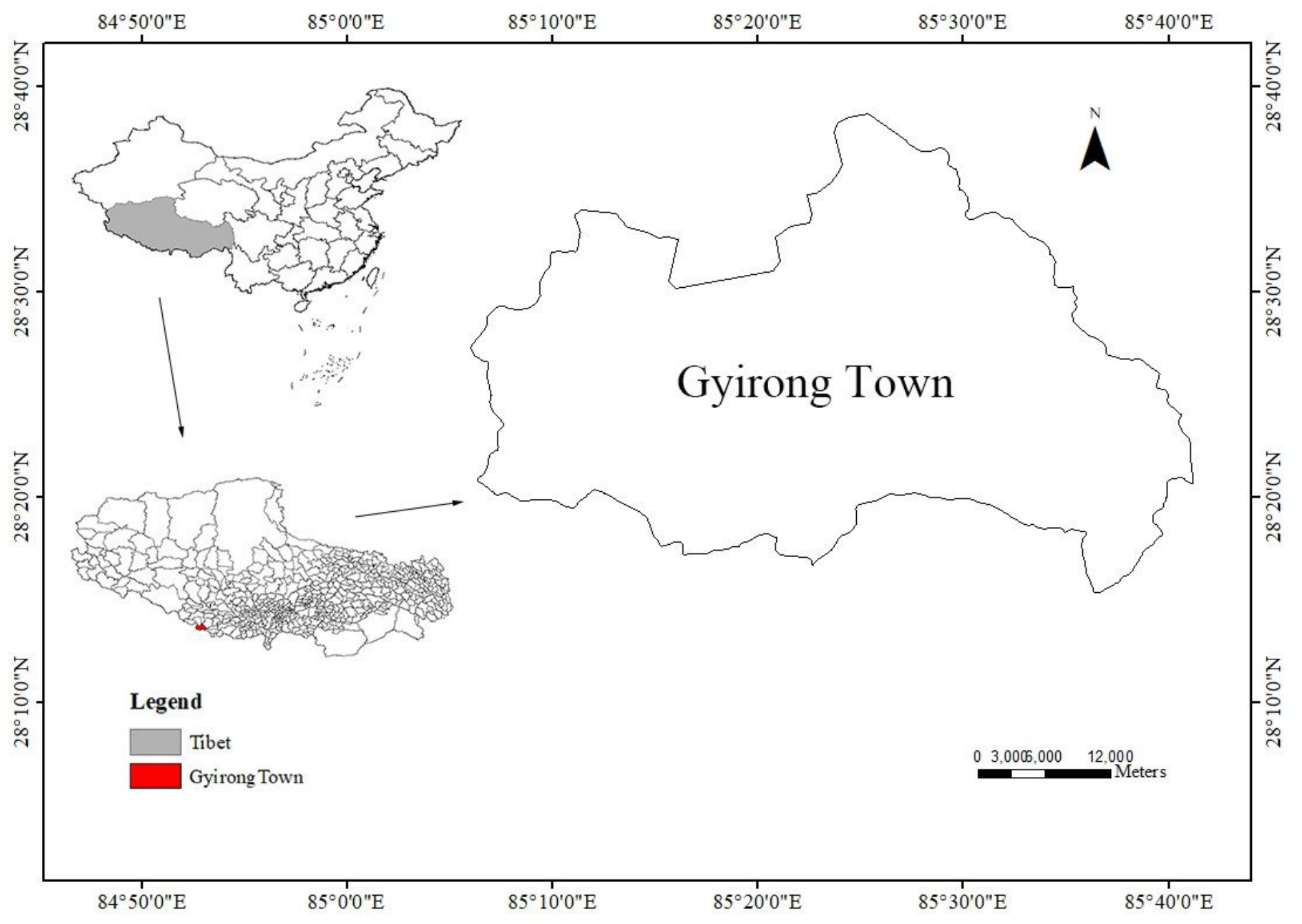

Figure 1

Study area: Gyirong Town, Tibet, China

2

Figure 2

Processing of wooden bowls. (a) Raw materials (the picture shows a burl of B. utilis); (b-d) Unfinished bowl, machine processing, and rough wooden bowl, respectively; (e-f) Yellow and red dye solutions; (g) Traditional lacquer plant (Impatiens falcifer); and ( $h$ ) Finished wooden bowls. 